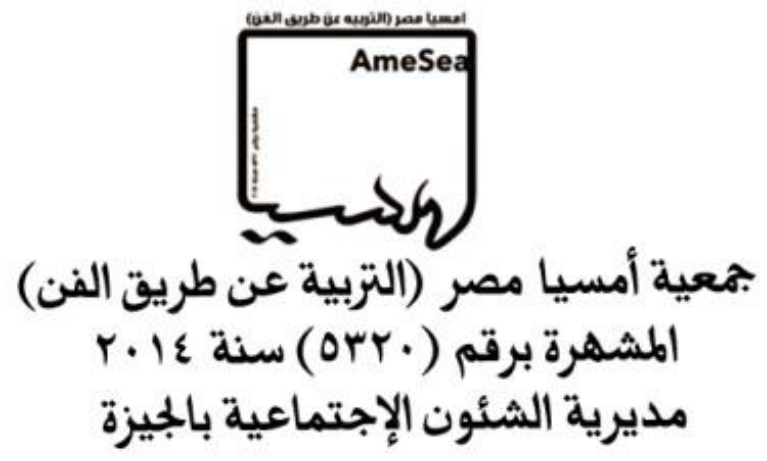

\title{
فن التيبوجرافى لنشر الوعى بصعوبات القراءة
}

Typography: Raising awareness of dyslexia

\author{
فادة هصطفى هممهد رشوان \\ مدرس التصميمات الزخرفية بقسم التربية الفنية \\ كلية التربية النوعية

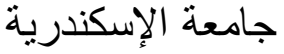

$$
5+11
$$


يو اجه بعض الأطفال صعوبات ضمن عملية القر اءة، تؤثز في الطريقة التي يتعلم بها الثخص

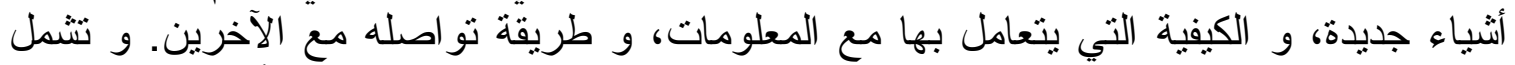

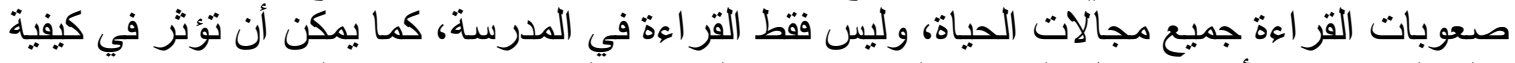

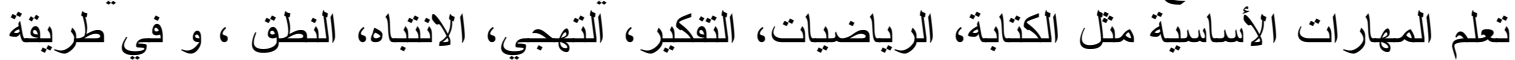

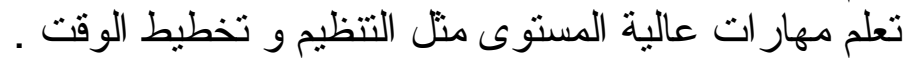

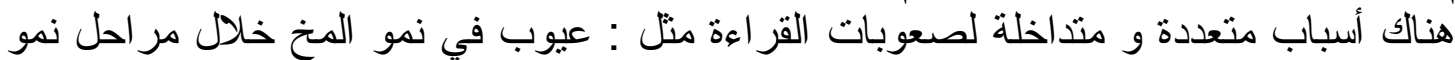

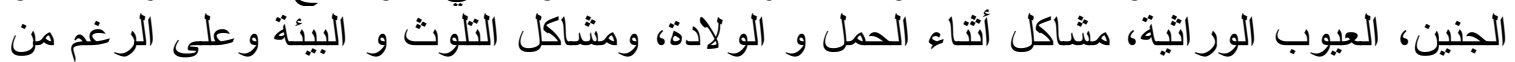

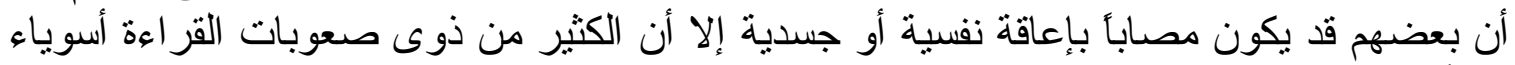
بل أن منهم موهوبين ومشهورين مثل ستيف جوب Steve Jobs، ستيفن سبيلبيرج

Spielberg يظهر الطلاب الذين يعانون من هذه الصعوبة قدرة منخفضة في اكتساب مهار ات القراعة الصابة

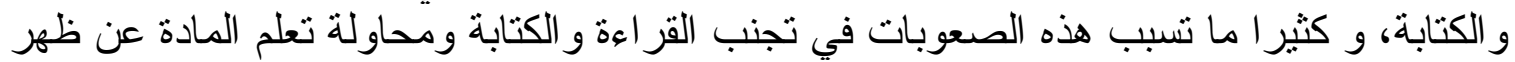

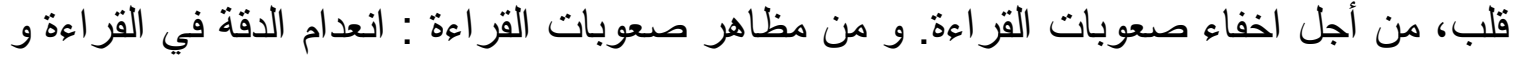

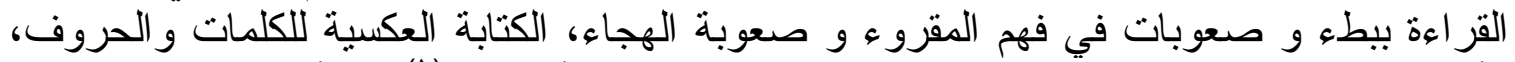

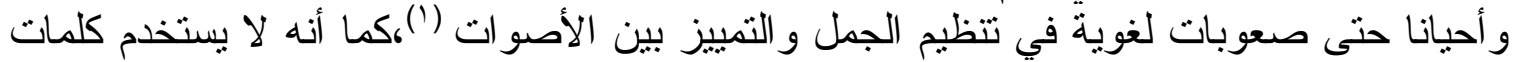

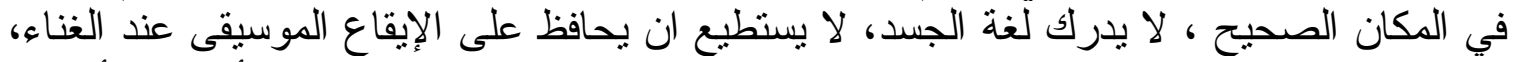

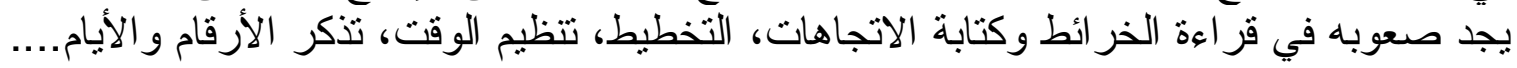

تتسم صعوبات القر اعة بصعوبات في إدر الك الكلمات بصورة صحيحة وقدر ات ضعيفة في فلك

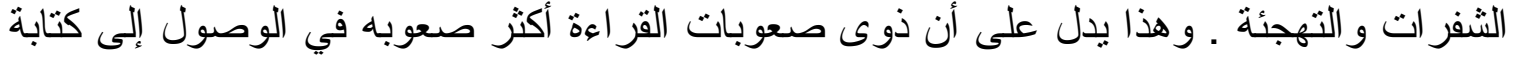

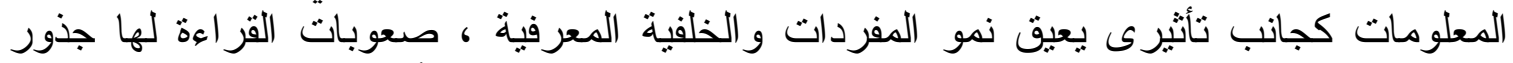

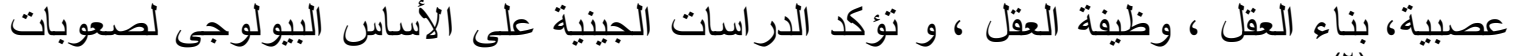

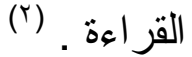

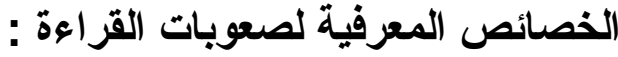

صعوبات القر اعة منتو عة الحالات وليس كل الحالات لها نفس الصعوبات و الخصائص، منها:-

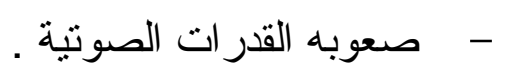

- - معوبه في الذاكرة قصبرة المدى .

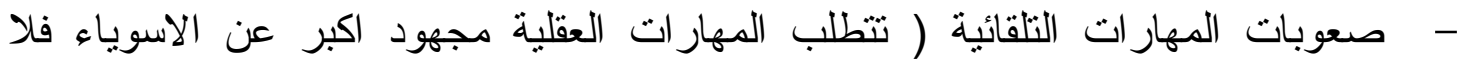
يستطيع ذوى صعوبات القر اعة حل تمارين متعددة المهار ات مثل القر اءة، الكتابة، السو اقه).

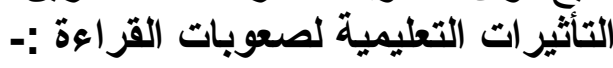

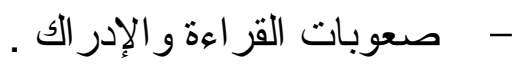

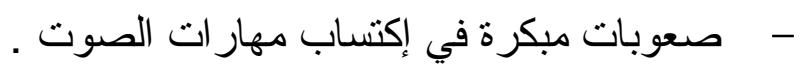

(1) http://www.new-educ.com

( $\left.{ }^{2}\right)$ "Good Fonts for Dyslexia", Luz Rello, Ricardo Baeza-Yates, Bellevue, Washington, USA, 2013 p2.

(AmeSea Database - ae -January- April. 2018- 0285) 


$$
\begin{aligned}
& \text { - - مسبة أخطاء كبيرة في القر اءة الثفهية . } \\
& \text { - - صعوبة في استخر اج المو اد المكتوبة بدون إعادة قر اعة جو هرية (أساسية) . } \\
& \text { - - القر اعة بسر عة بطيئة . }
\end{aligned}
$$

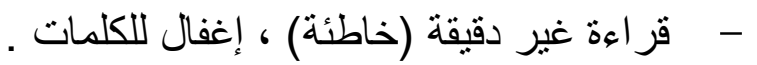

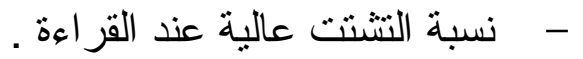

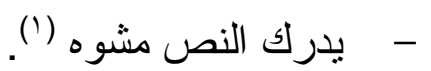

اهتم التربوبين بصعوبات القر اعة وكذلك المصممبين حيث صمم المصمم الجر افيكى " دانيال

بريتون Daniel Britton " فونت للكتابة شكل رقم ( (1) يوضح فقرة باللغة الانجليزيه تعطى

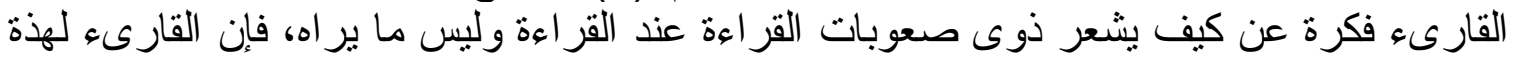
الفقرة لا يستطيع قراء اعتها بسهولة واذا استطاع فسيأخذ وقت أطول من قر اعة نفس الفقرة ولكن

بالخط العادى (r)

$$
\begin{aligned}
& \text { III I ग ग } 3 \Lambda \text { गा }
\end{aligned}
$$

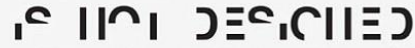

$$
\begin{aligned}
& \text { In ZEN } Z \equiv \Lambda I \equiv I / I / \Lambda I
\end{aligned}
$$

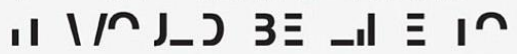

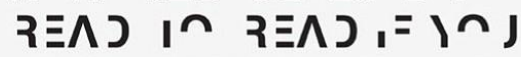

$$
\begin{aligned}
& \text { IIEZE गव_En I I }
\end{aligned}
$$

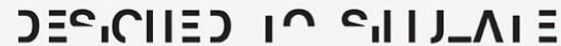

$$
\begin{aligned}
& \text { IIIE =EE_ll } n=3 \equiv \Lambda J_{I I I C} \\
& \text { |/II| כ)_En॥ 3| } \\
& \text { c_nIIIC IIIE zE八JIIC } \\
& \text { IIIE } n=\text { IIIE /IEIIEZ }
\end{aligned}
$$

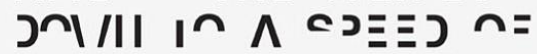

$$
\begin{aligned}
& \text { I/III कn IIEnIE I/In } \\
& \text { IIA }
\end{aligned}
$$

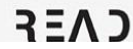

" Daniel Britton شكل رقم( ( ) يوضح فقرة بأبجدية المصمم الجر افيكى " دانيال برينون

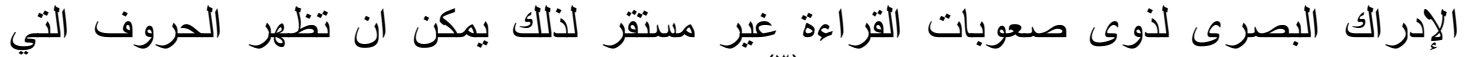

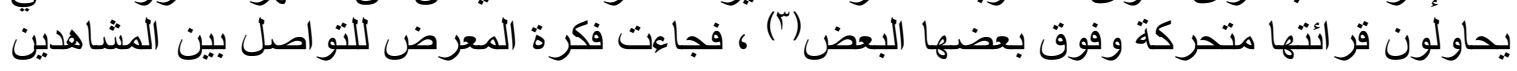
وذوى صعوبات القر اءة و التعرف دن خلال اللوحات على سمات القر اءة لديهم وتوصيل رسائل

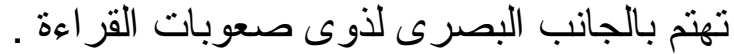

( $\left.{ }^{1}\right)$ "Understanding Dyslexia, Introductory Notes", Lucid Research Ltd, F19 v 02.3 Apr 2006, p3,4 www.Lucid-Research.com

$\left.{ }^{2}\right)$ http://metro.co.uk/2015/06/06/this-is-what-it-is-like-to-have-dyslexia5232994/\#ixzz482MyLsoh

$\left(^{3}\right)$ John Stein: "the Magnocellular Theory of Developmental Dyslexia", university laboratory of physiology, Oxford, UK, john Wiley \& sons. Ltd , 2001, p1

(AmeSea Database - ae -January- April. 2018- 0285) 
وترى الباحثة ان مجال التصميم يقع على عاتقه إيجابية التفاعل بين الفرد و المجتمع ، و أنه يمكن من خلال تصميمات جر افيكية تيبو غر افية تتسم بالوضوح و والبساطة و التعبير إيصال رسائل الئل و اضحه للمجتمع، حيث يصف التصميم الجر افيكي التنظيم الواعي للنص و و / أو الصور لتونيل لتوصيل

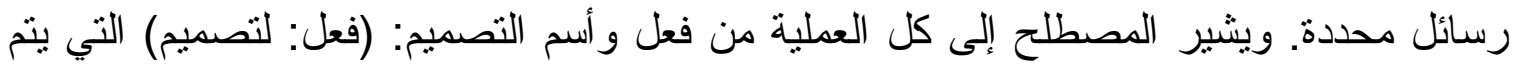

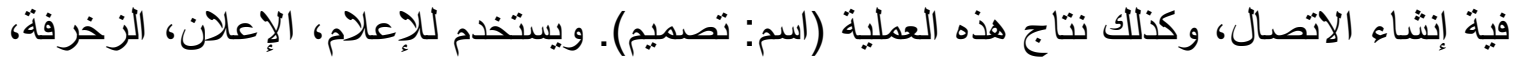

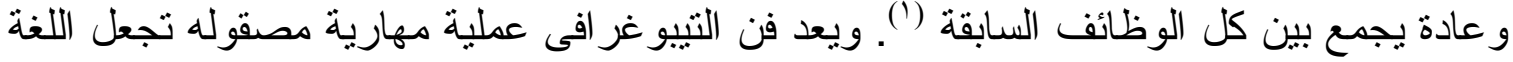

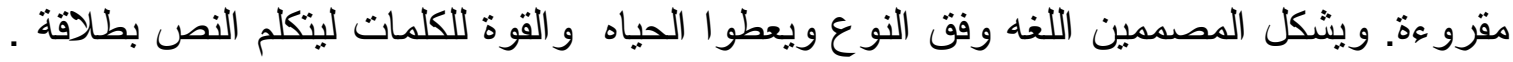
فالحروف التيبوغر افية ( الطباعية) هي بنائية مجردة أو صور بدون نص للإتصال، سهل جميل

يصنع الوضوح (؟)

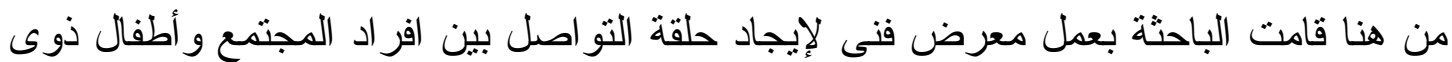

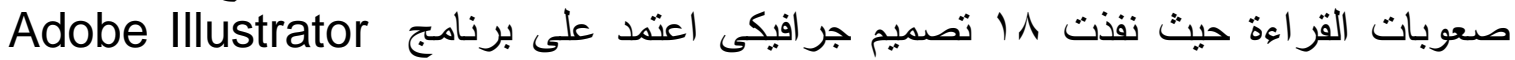

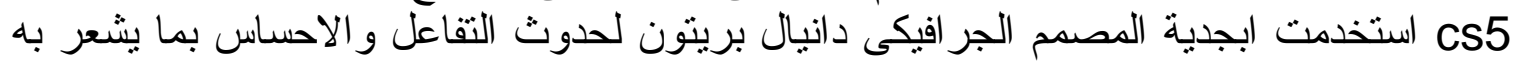

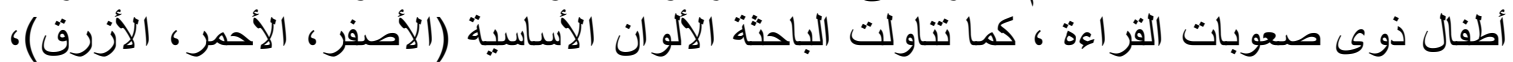

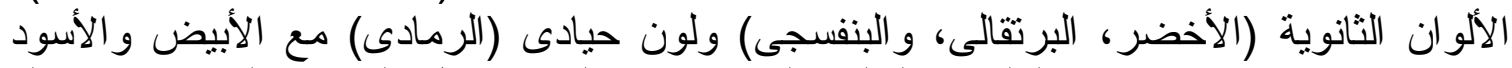

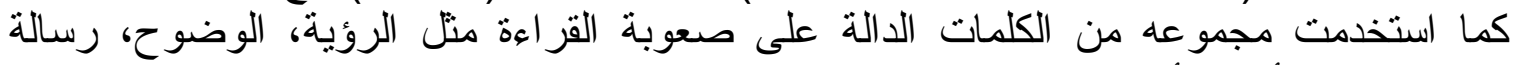
.... غير ها ، و الأرقام بأساليب تصميمة مختلفه تجذب المشات المشاهد.

$$
\text { أهداف المعرض : المعرض :- }
$$

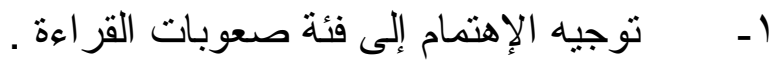

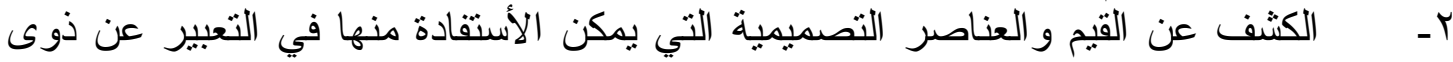
صعوبة القر اعة.

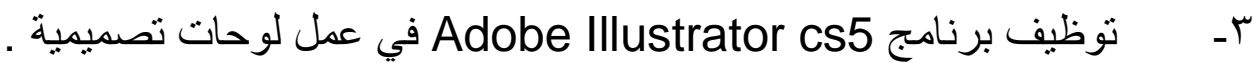

$$
\text { ترجع أهمية المعرض :- المعرض إلى:- }
$$

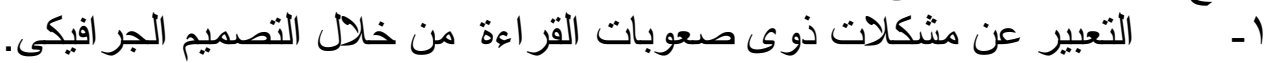

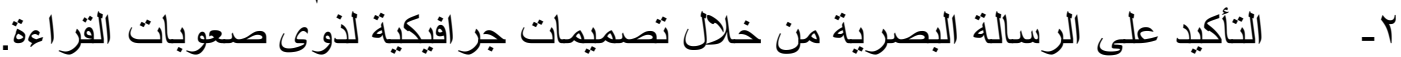

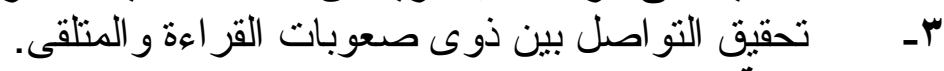

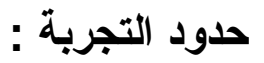

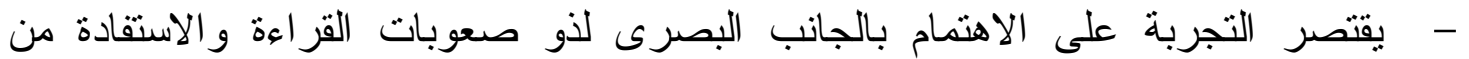
المتغير ات اللغوية الثكلية للحروف ولانئ الأرقام و الأشكال.

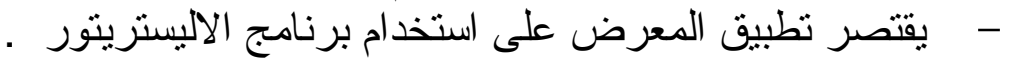

( $\left.{ }^{1}\right)$ Michal Erlhoff, Tim Marshall:" Design Dictionary", Birkhäuser Verlag AG, Berline 2008, p 196

$\left(^{2}\right)$ Kristin Cullen:" Design Elements Typography", Fundamentals Rockport publishers, 2012, p 12

(AmeSea Database - ae -January- April. 2018- 0285) 


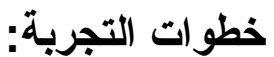

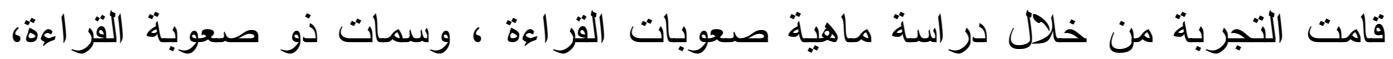

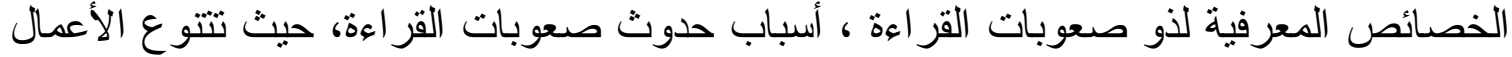

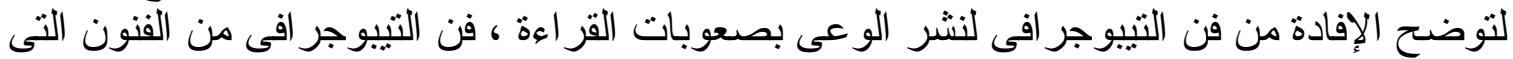

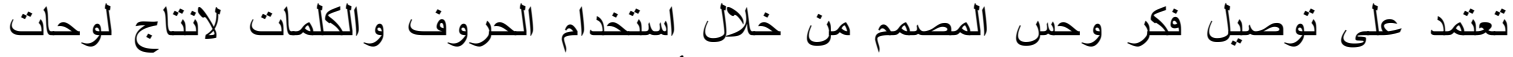
تصميمية تتسم بالبساطة و التعبير مع مر اعاة عناصر و وأسس التصميم العلاقات الإنشائية. يتضمن المعرض ب محاور:

المحور الأول : تصميم أعمال تعتمد على التعبير الصورئ الصورى ( أشكال - رموز)

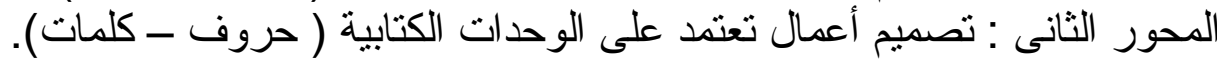

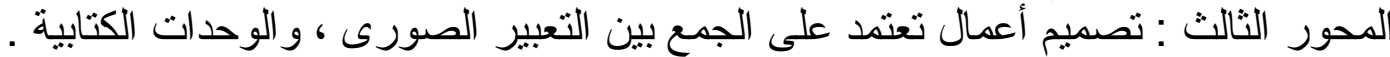

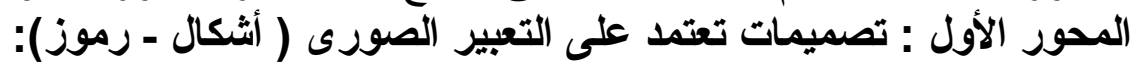

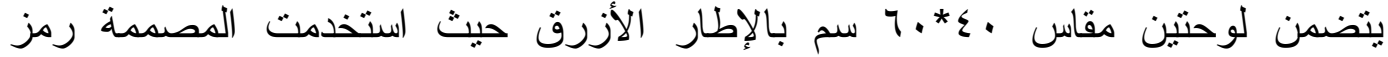

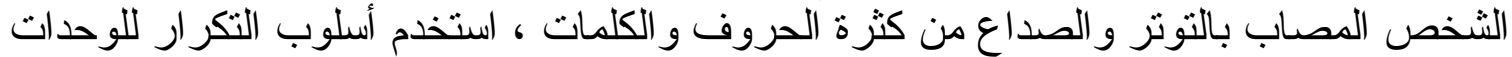

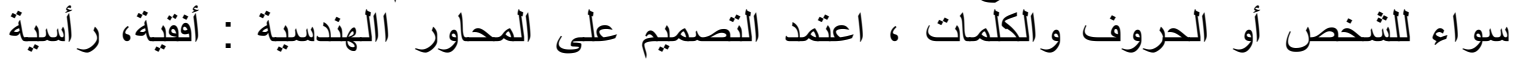

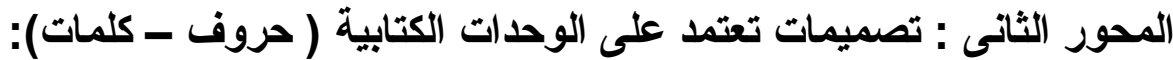

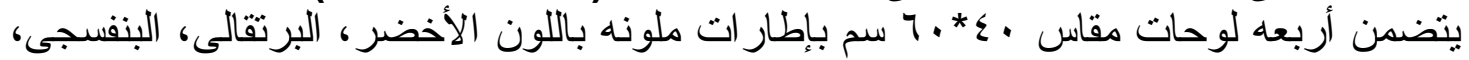

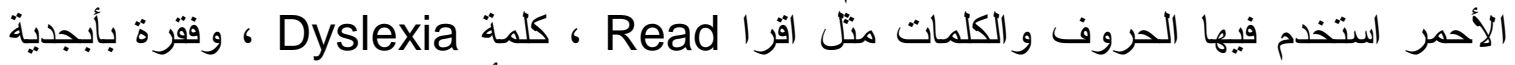

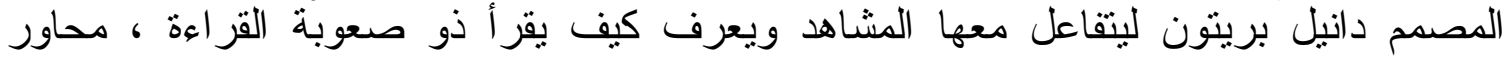

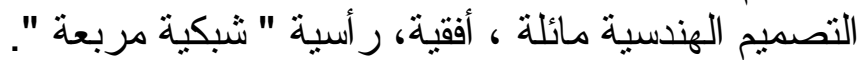

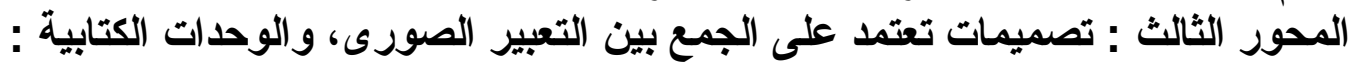

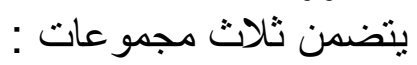

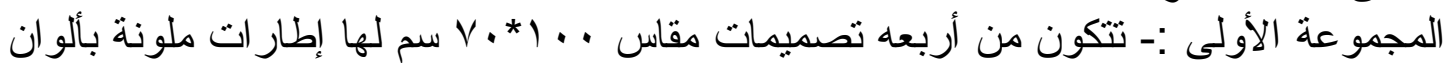

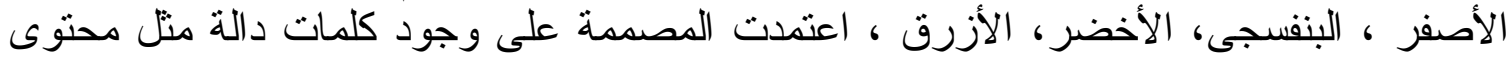
Concept

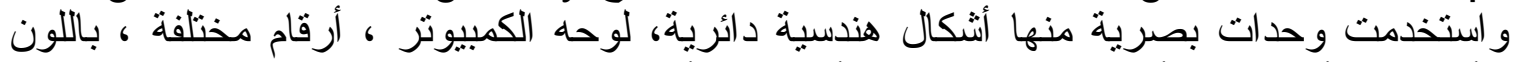
الأزرق و الأخضر و الأصفر و البنفسى و الأبيض و الأسود لجذب التبه انتباه المشاهد، محاور التصميم :

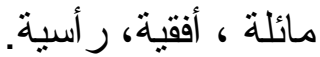

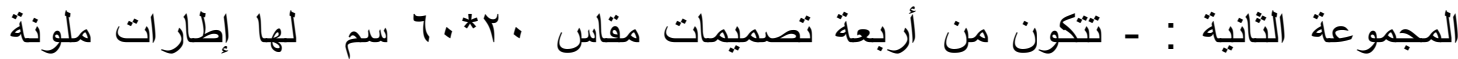
بالأخضر، الأزرق، أصفر تتاول فيها شكل العقل، مساحات هندسية منتظمة ، محاور التصميم : مائلة ، أفقية، ر أسية، دائرية.

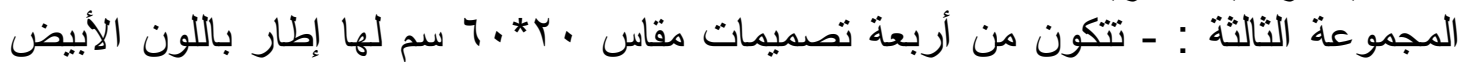

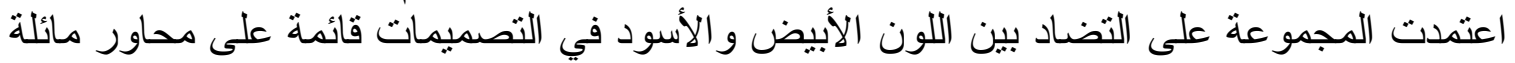

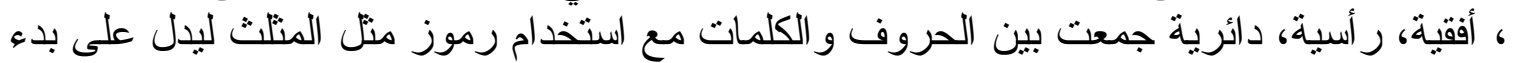

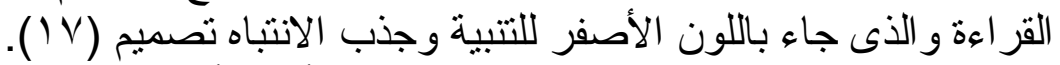

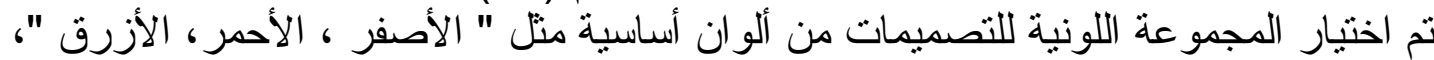

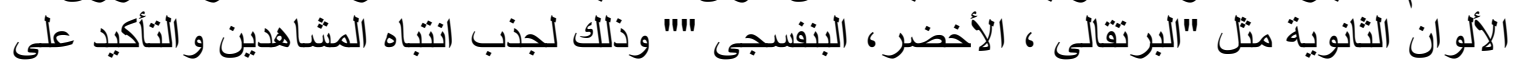

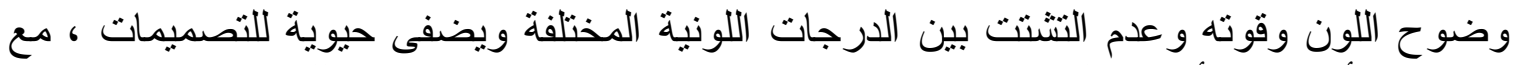

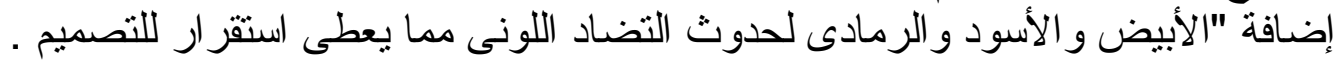

(AmeSea Database - ae -January- April. 2018- 0285) 
المحور الأول : تصميمات تعتمد على التعبير الصورى ( أثنكال - رموز):-

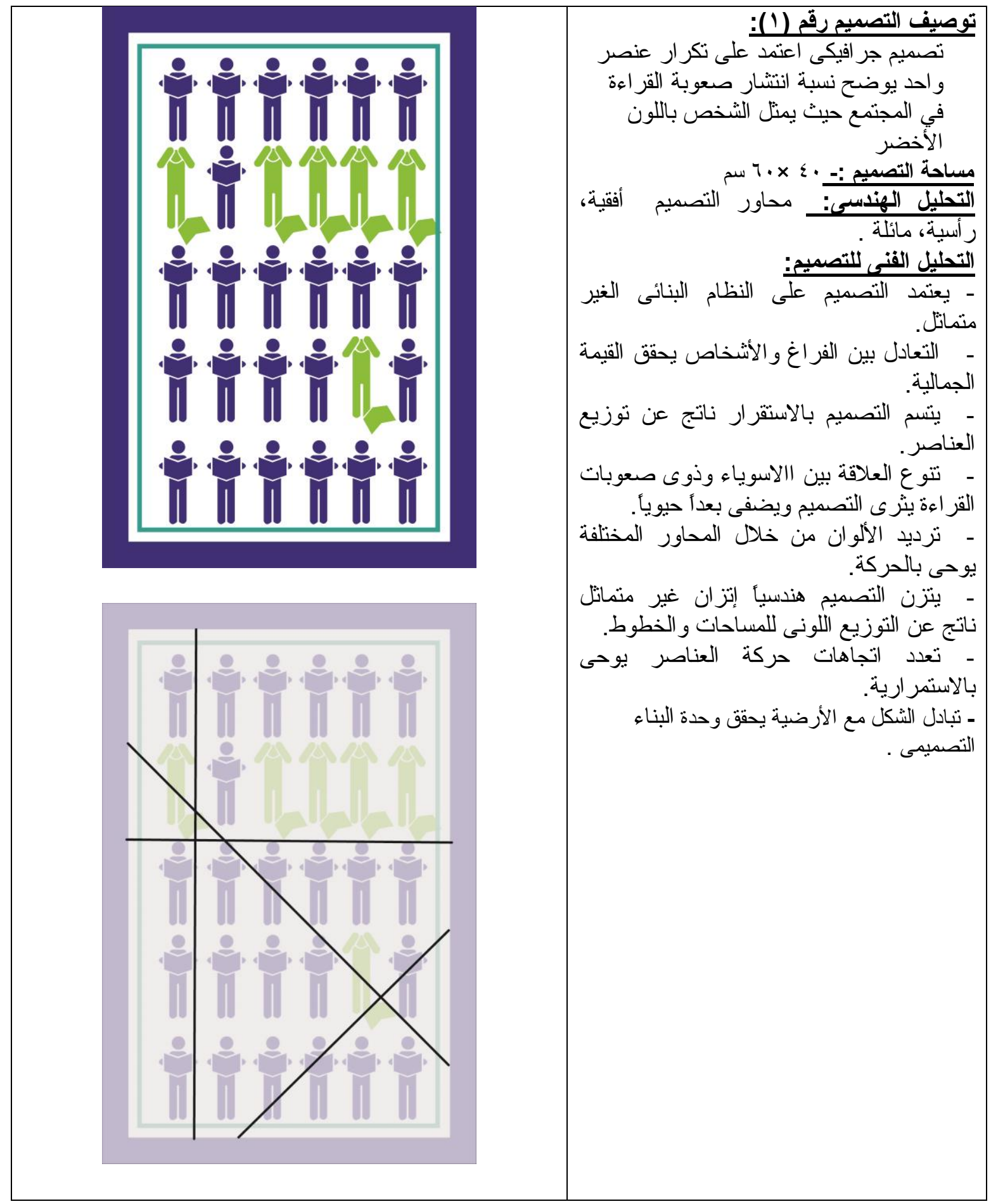

(AmeSea Database - ae -January- April. 2018- 0285) 


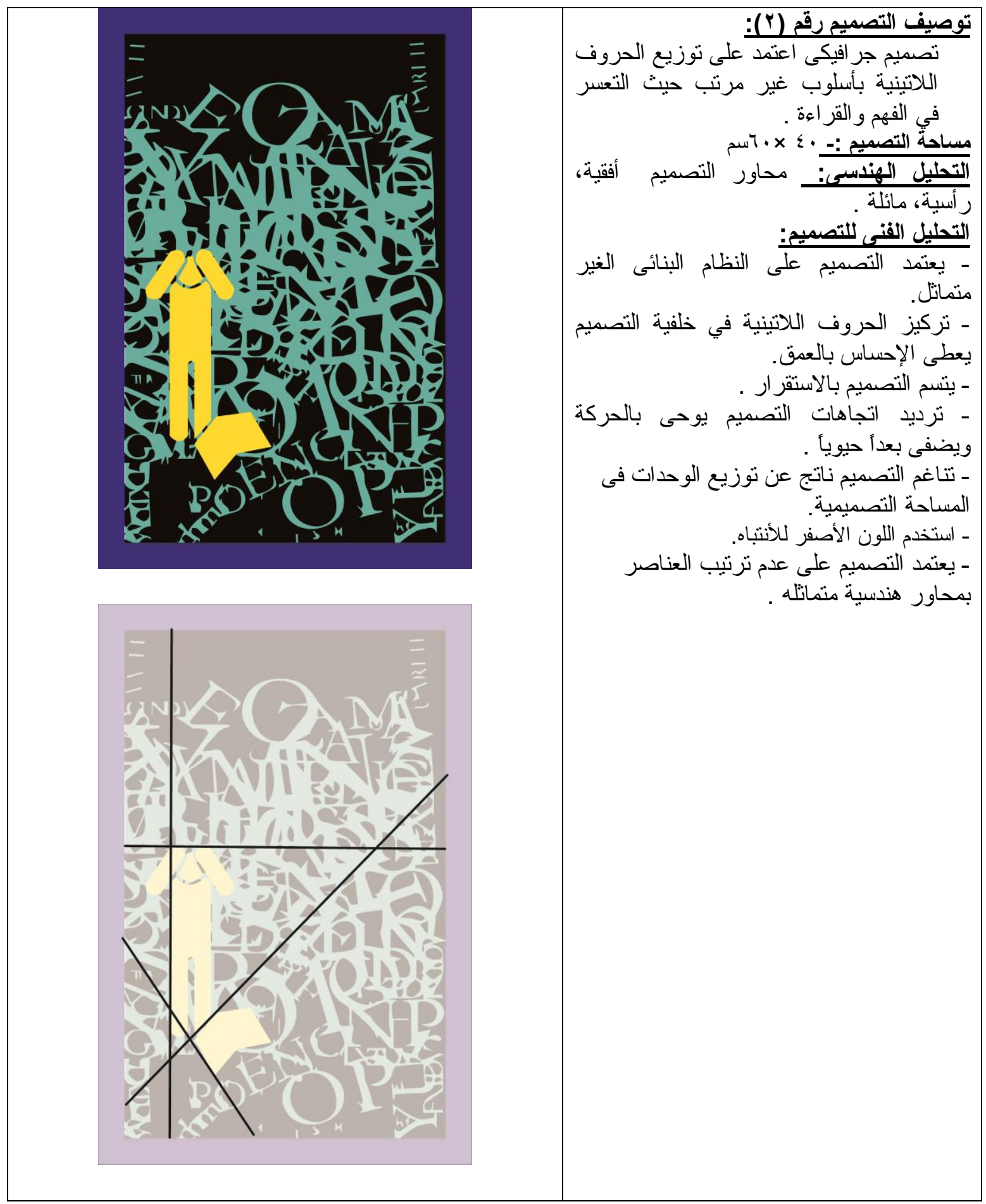

(AmeSea Database - ae -January- April. 2018- 0285) 
المحور الثانى : تصميم أعمال تعتمد على الوحدات الكتابية ( حروف ـ كلمات):-

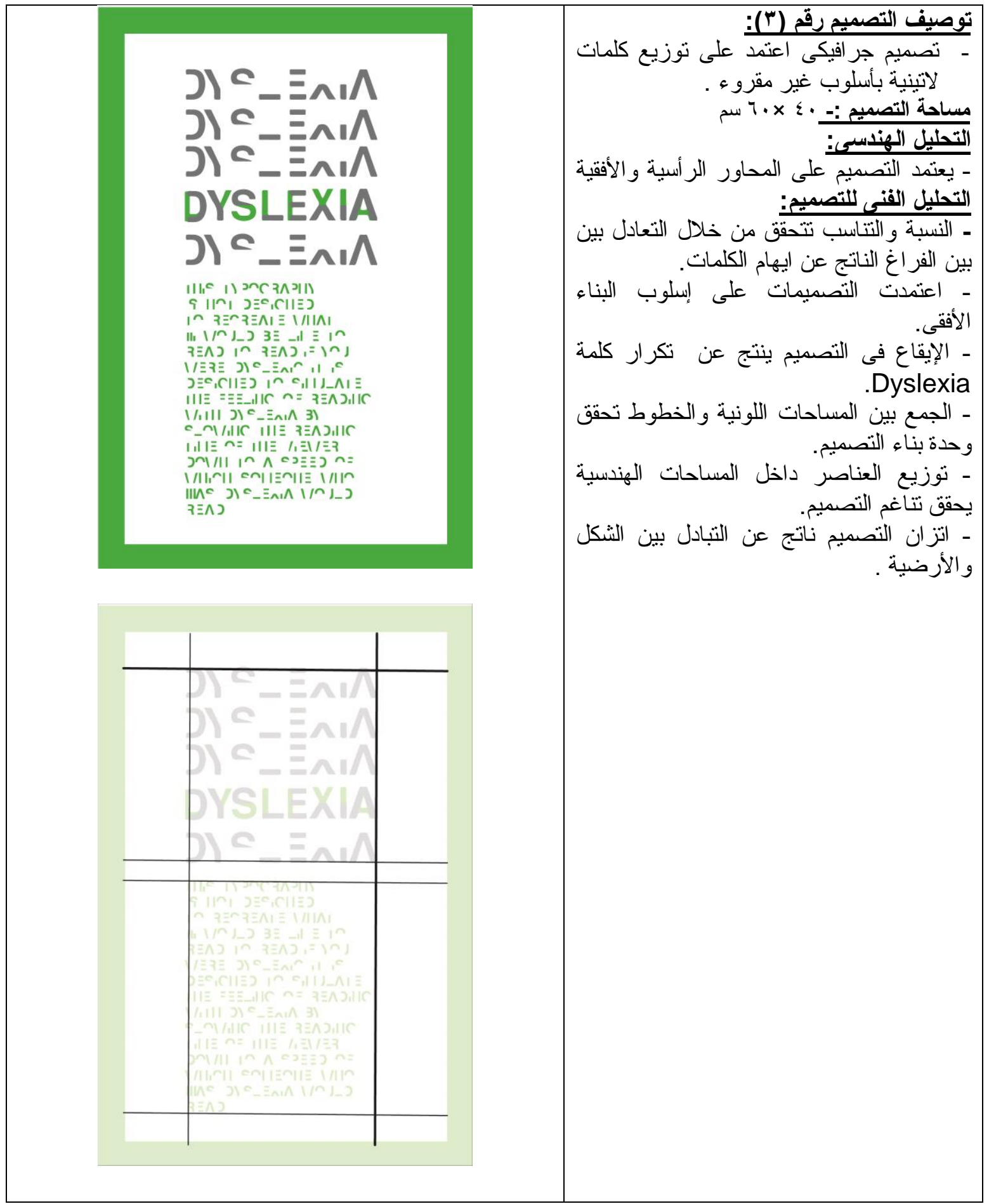

(AmeSea Database - ae -January- April. 2018- 0285) 


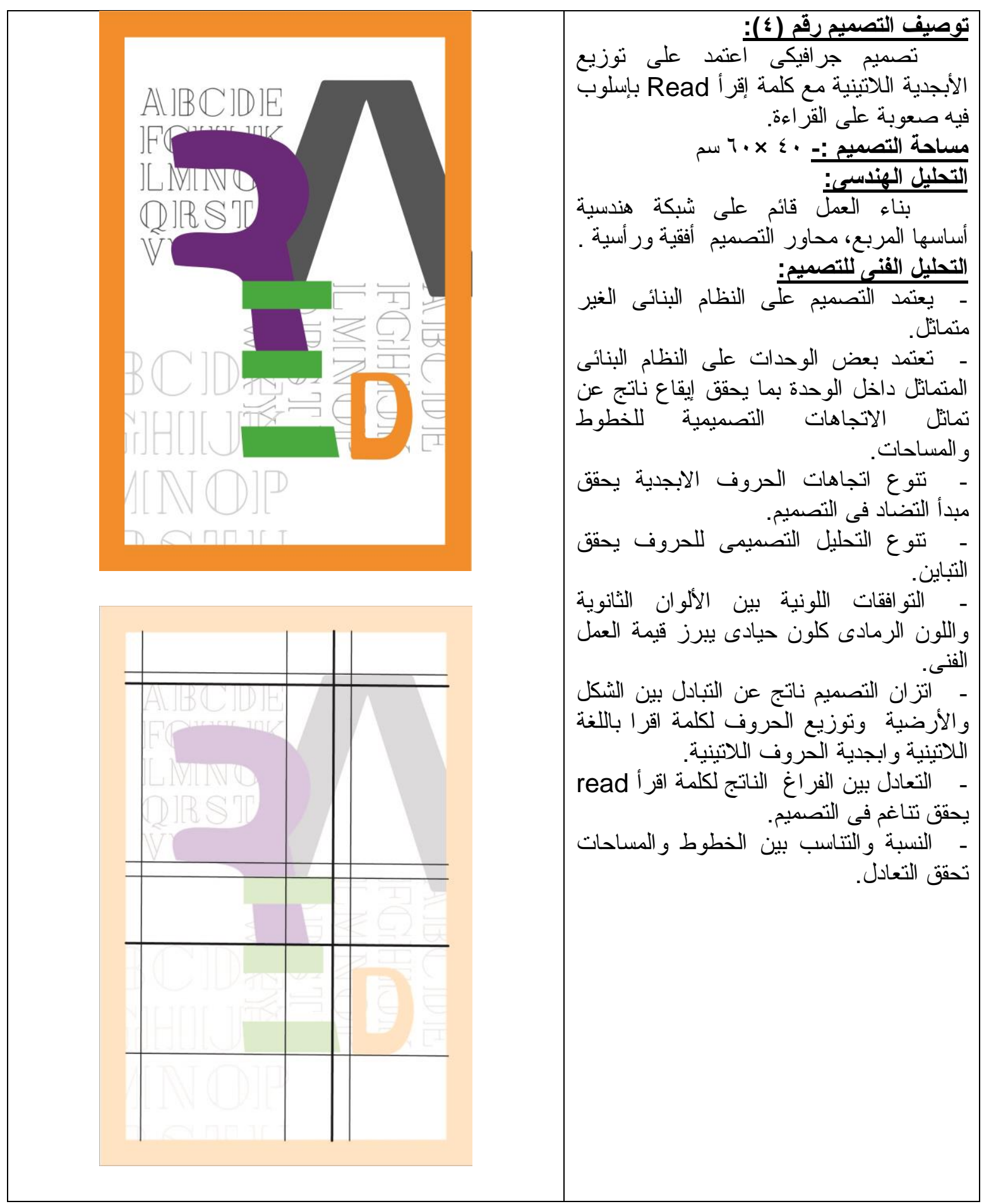

(AmeSea Database - ae -January- April. 2018- 0285) 


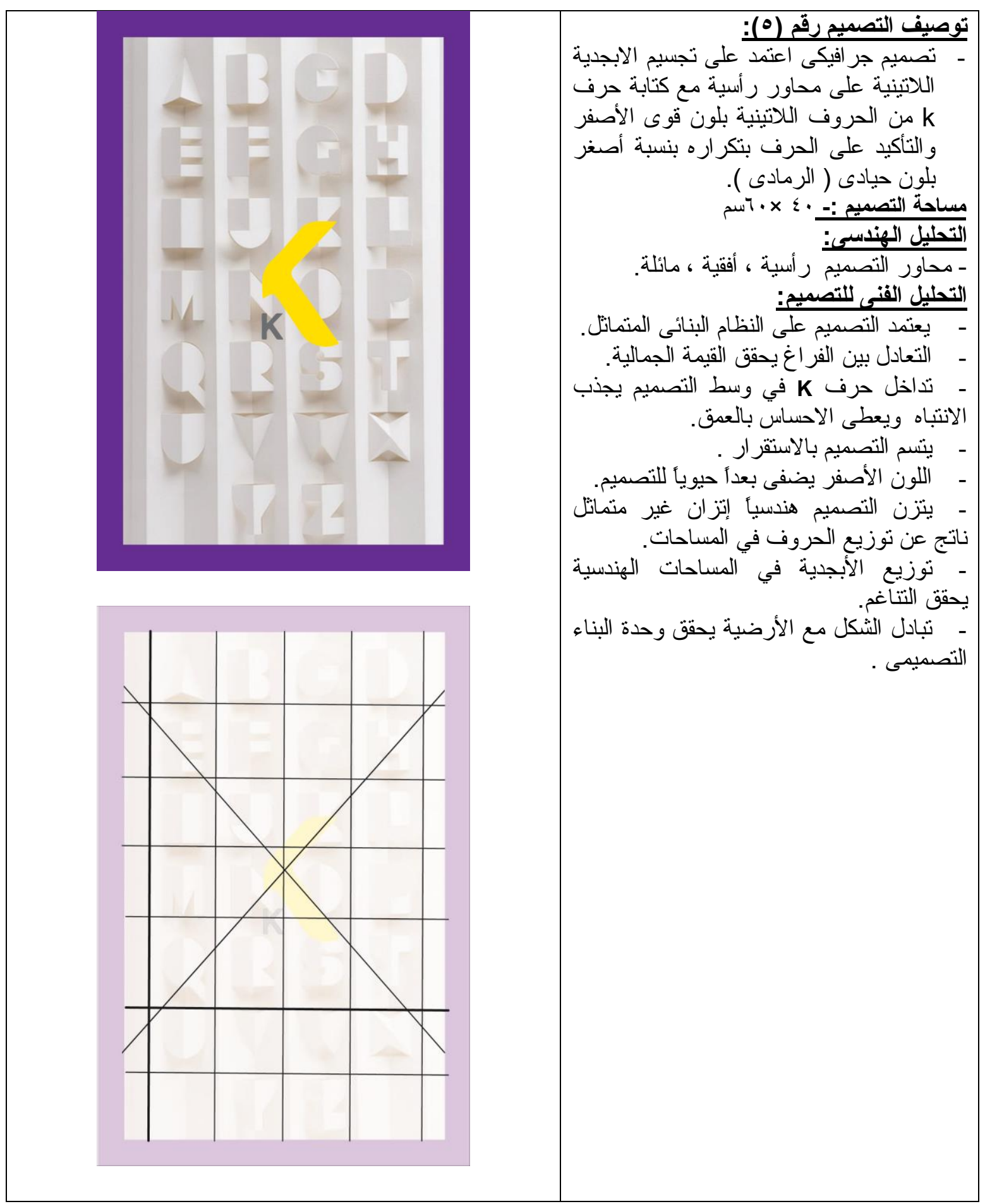

(AmeSea Database - ae -January- April. 2018- 0285) 


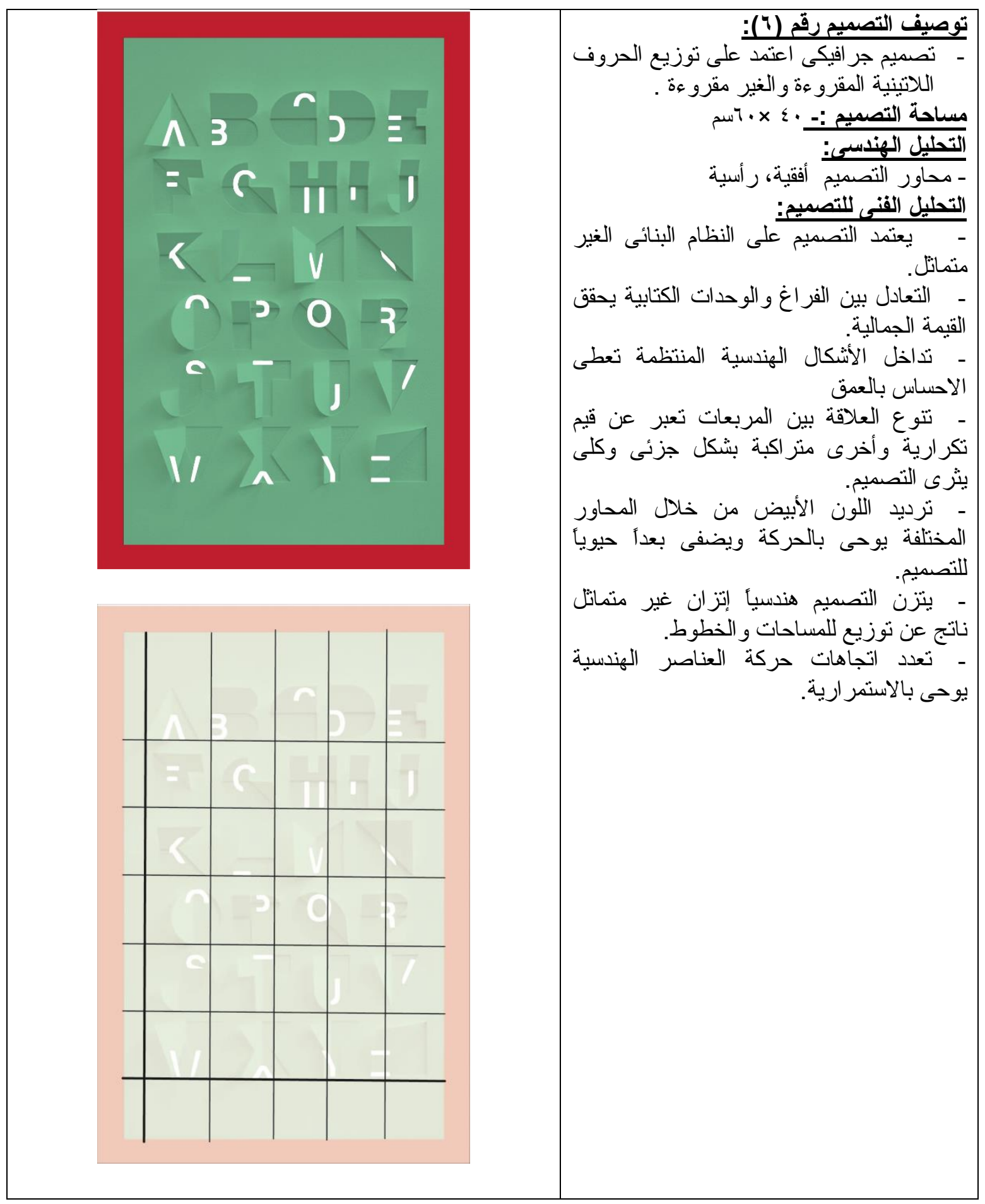

(AmeSea Database - ae -January- April. 2018- 0285) 
المحور الثالث: تصميم أعمال تعتمد على الجمع بين التعبير الصورى،والوحدات الكتابية:-

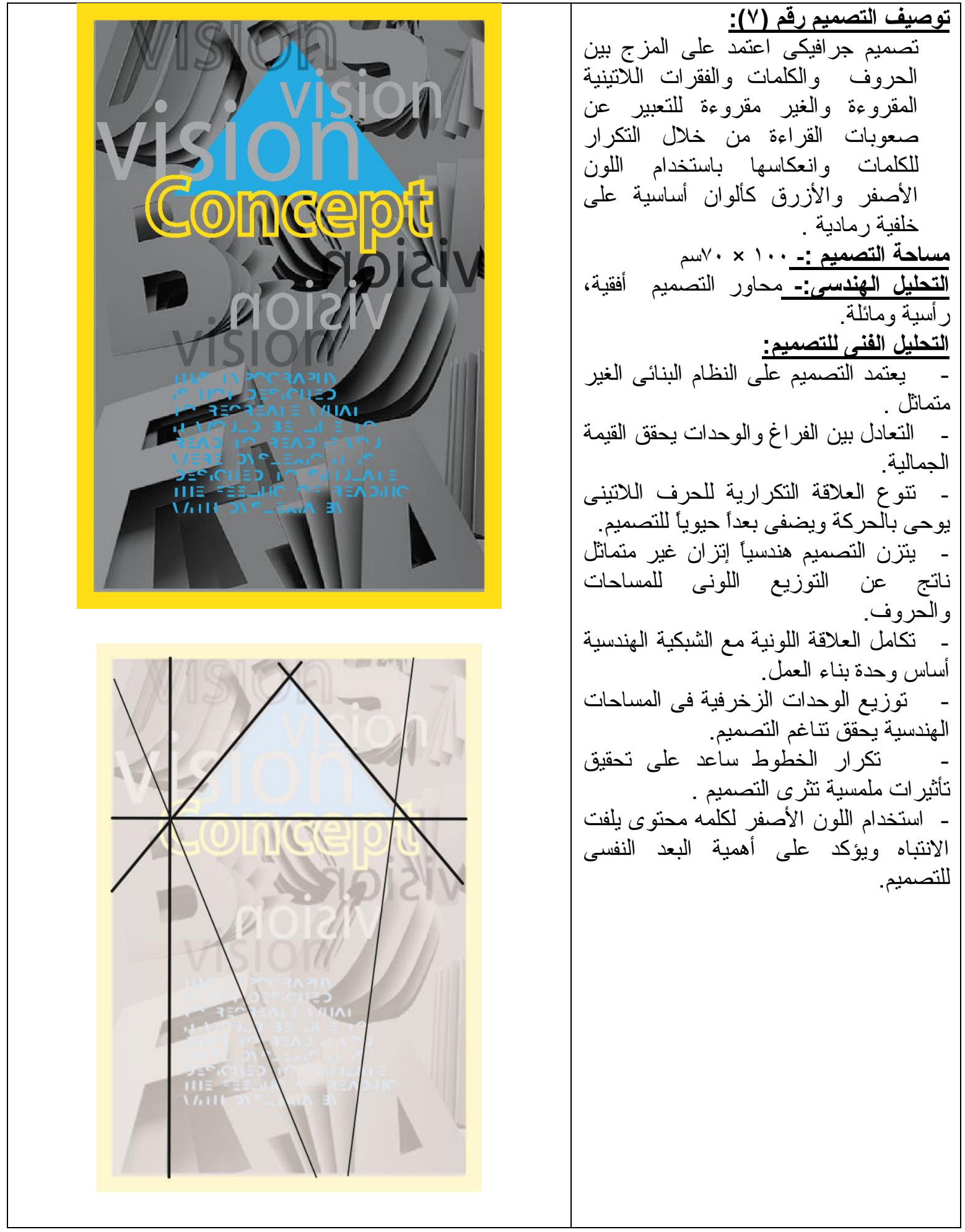

(AmeSea Database - ae -January- April. 2018- 0285) 


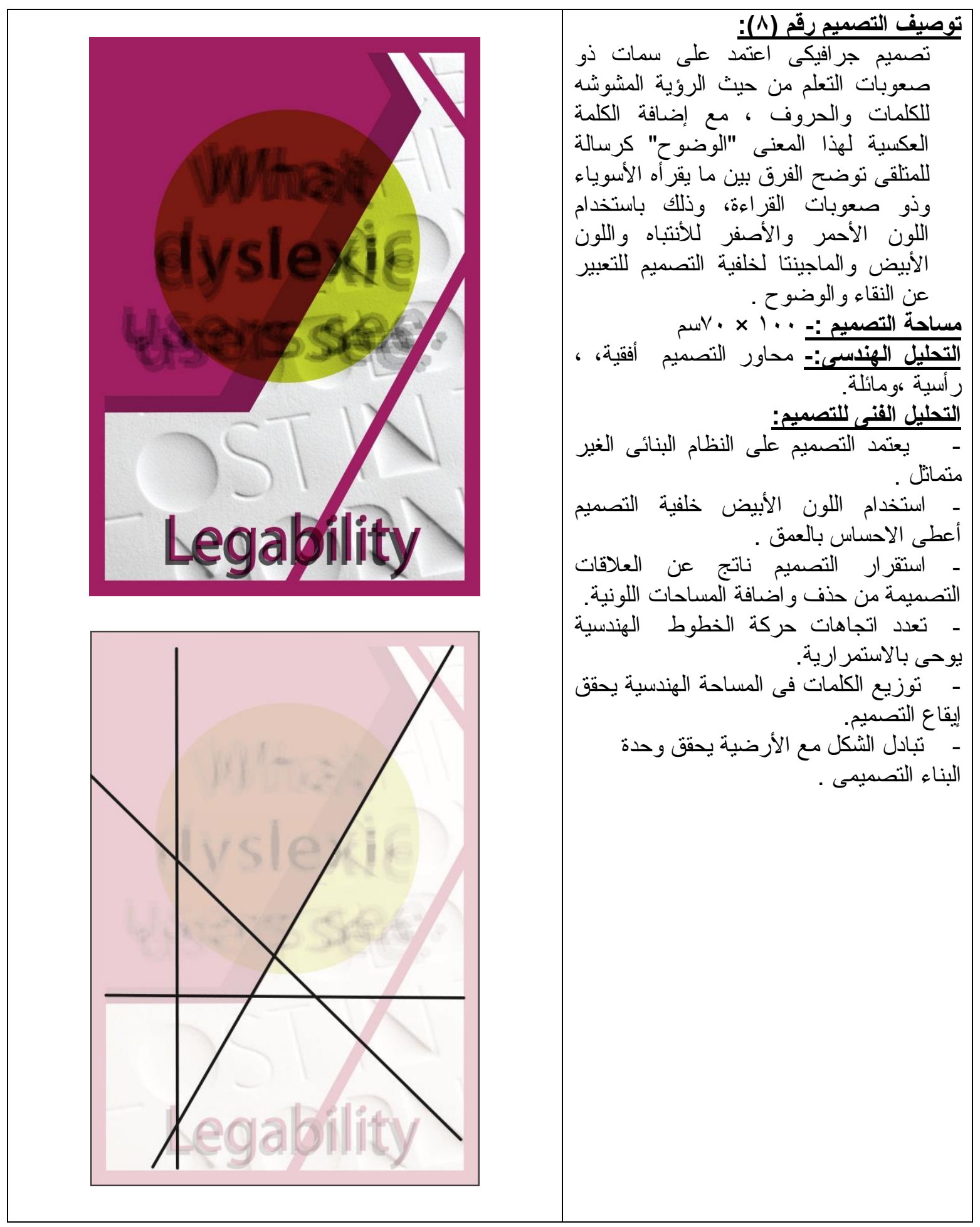

(AmeSea Database - ae -January- April. 2018- 0285) 


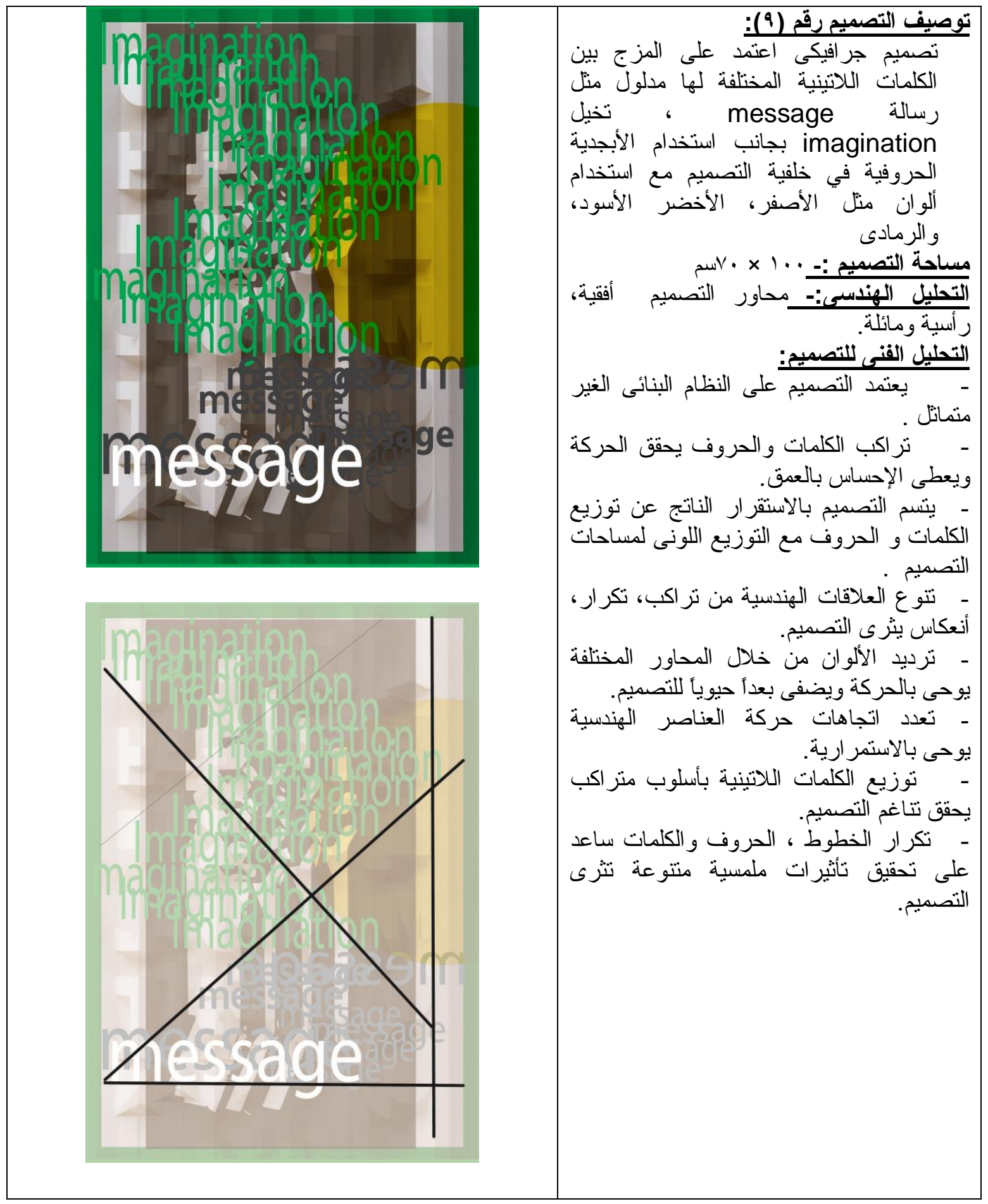

(AmeSea Database - ae -January- April. 2018- 0285) 


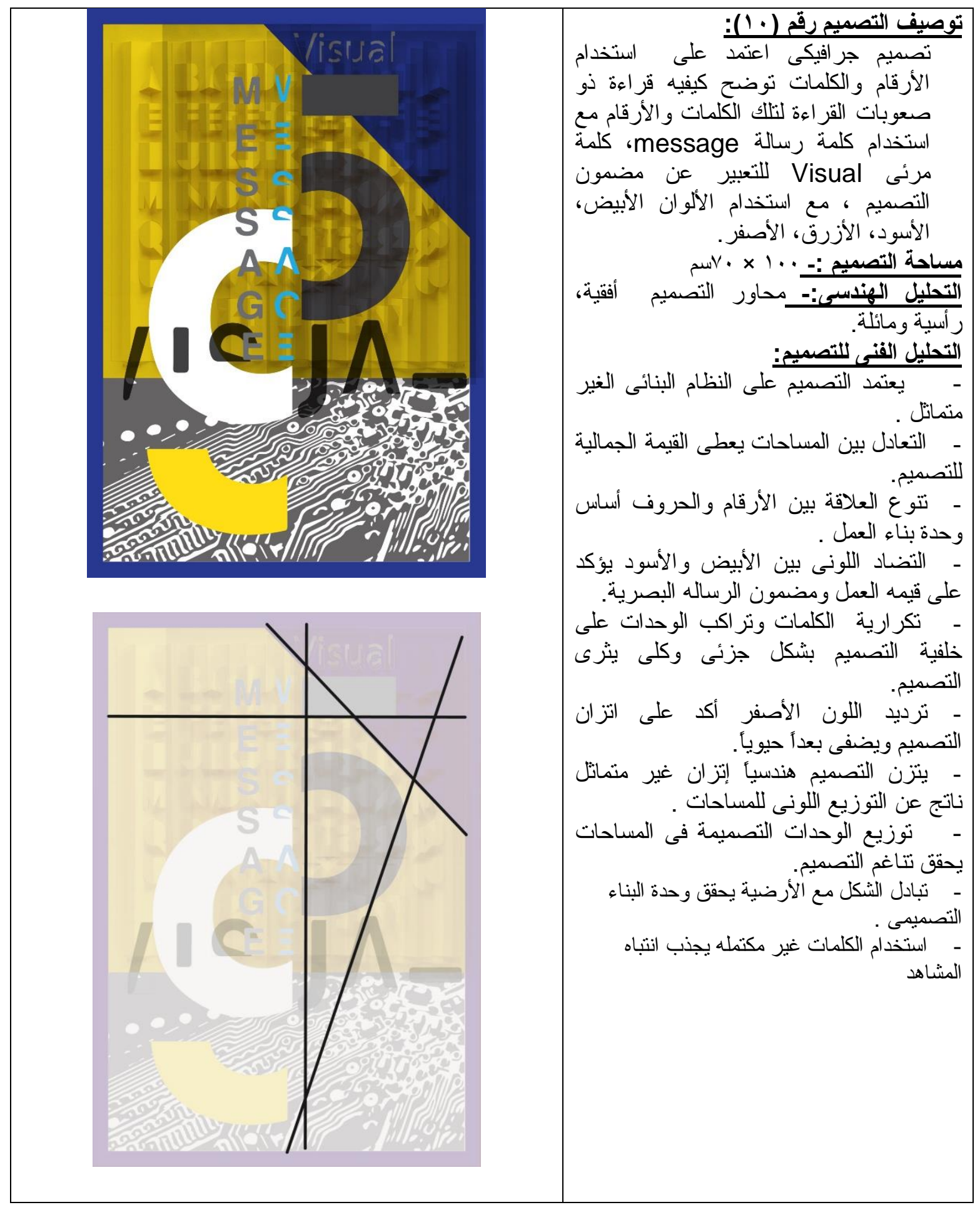

(AmeSea Database - ae -January- April. 2018- 0285) 


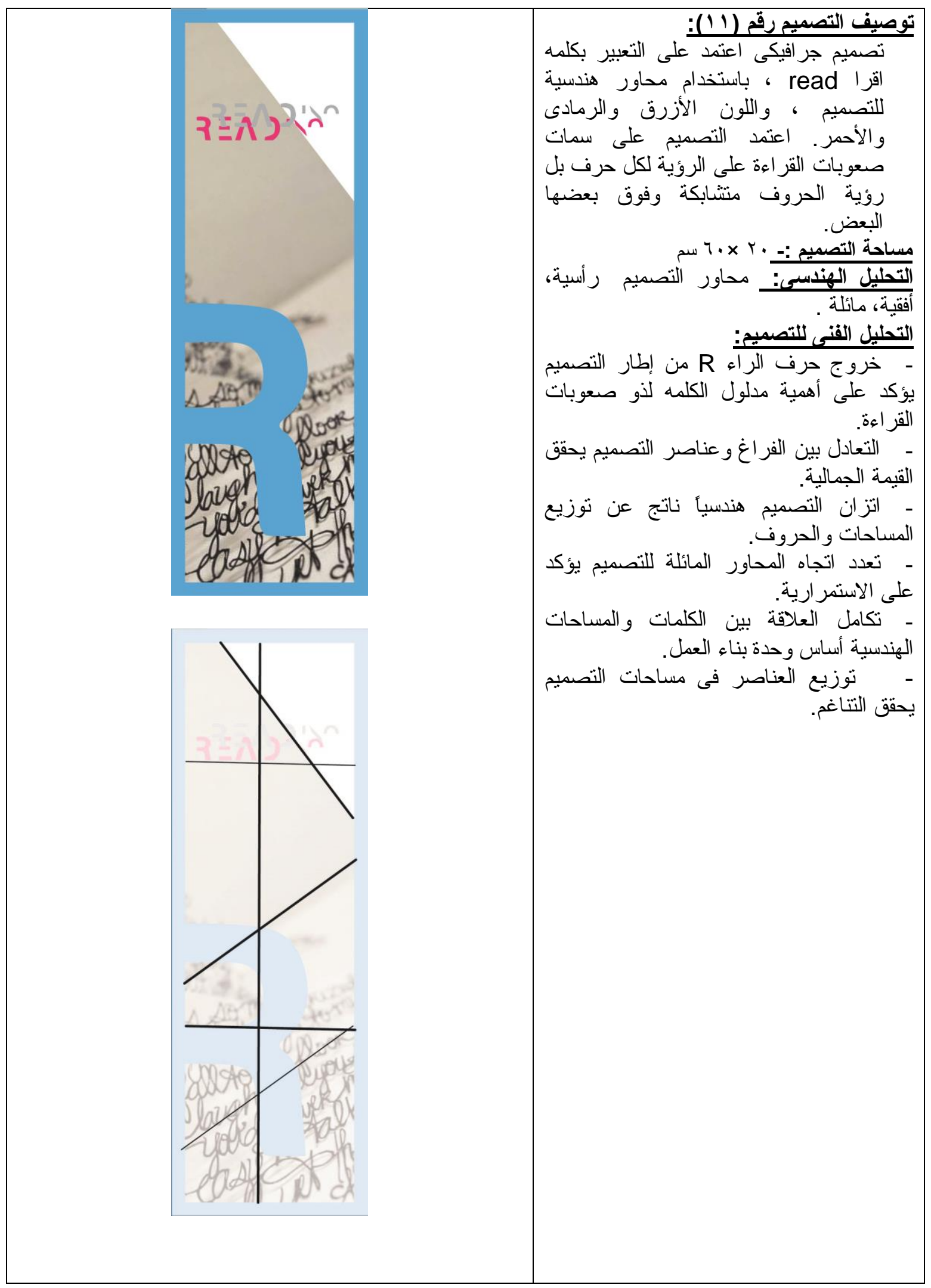

(AmeSea Database - ae -January- April. 2018- 0285) 


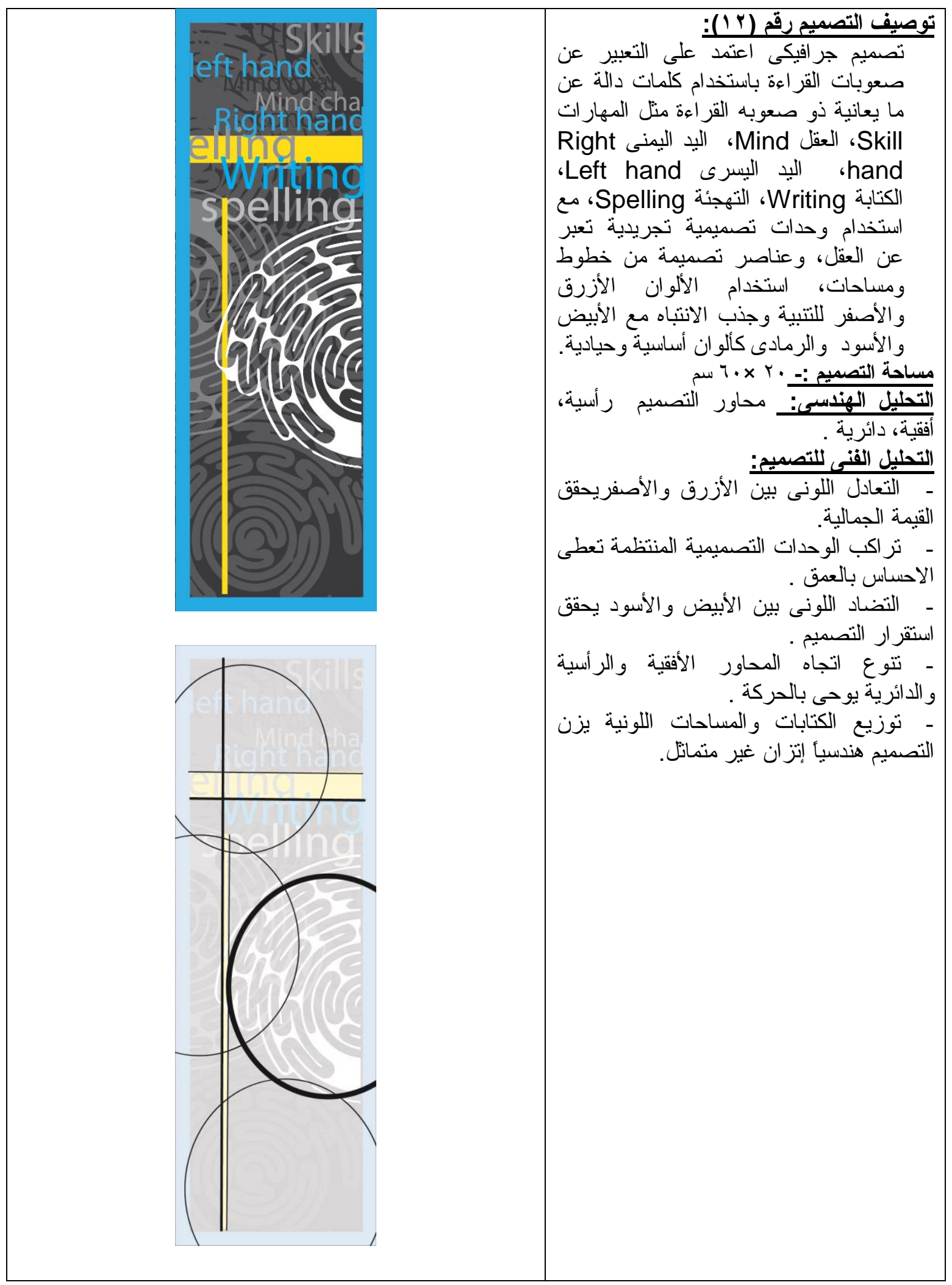

(AmeSea Database - ae -January- April. 2018- 0285) 


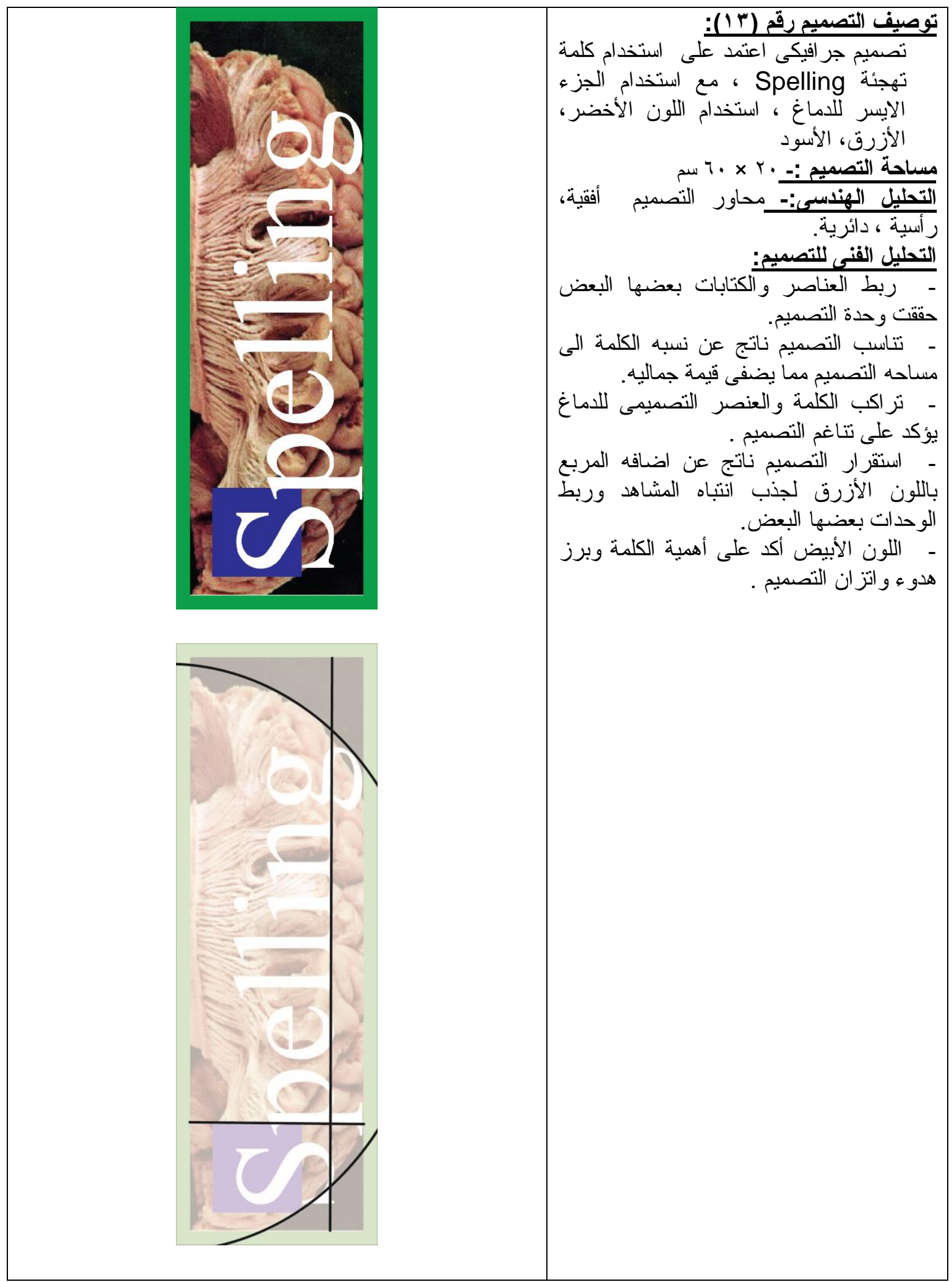

(AmeSea Database - ae -January- April. 2018- 0285) 


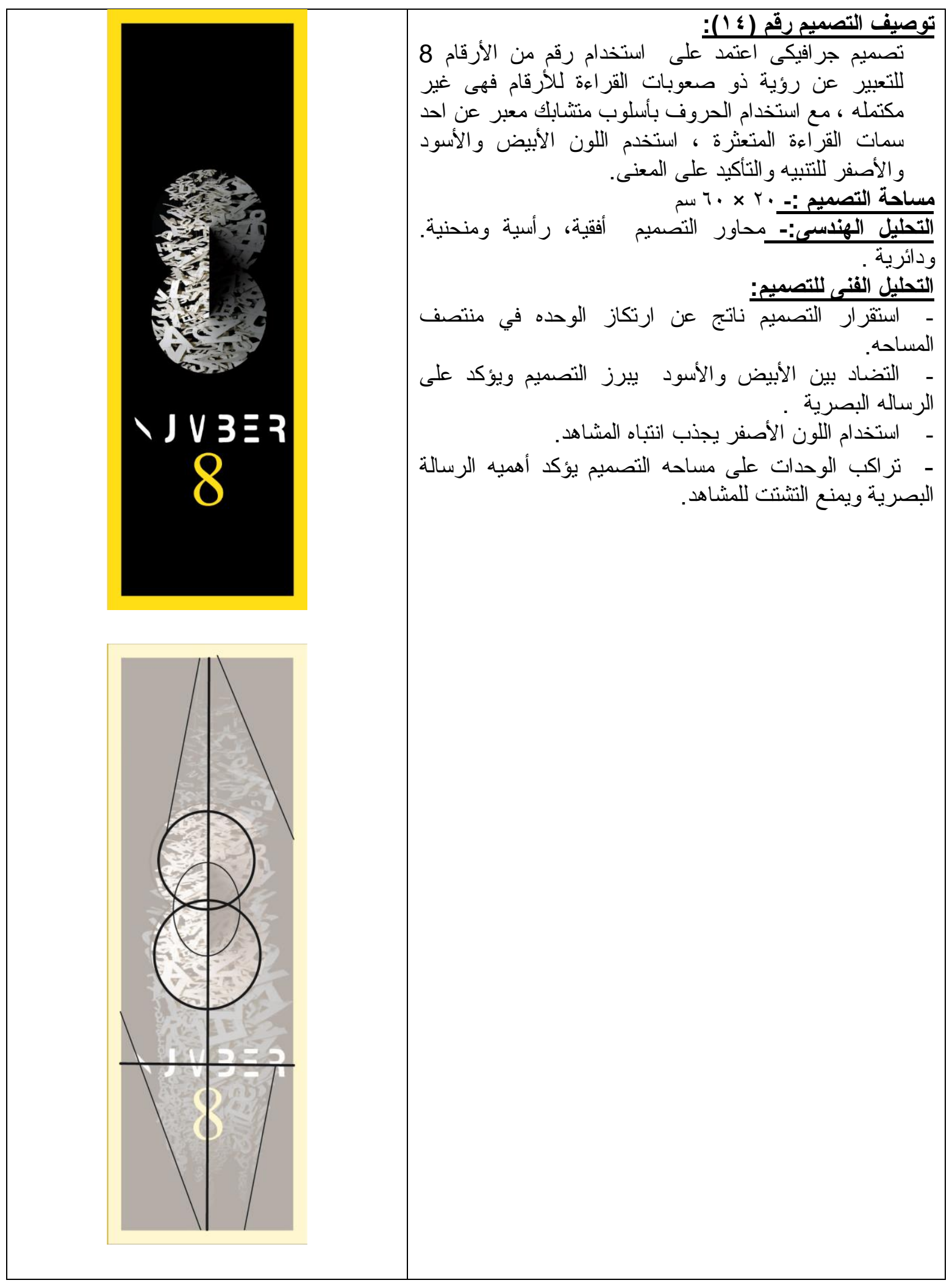

(AmeSea Database - ae -January- April. 2018- 0285) 


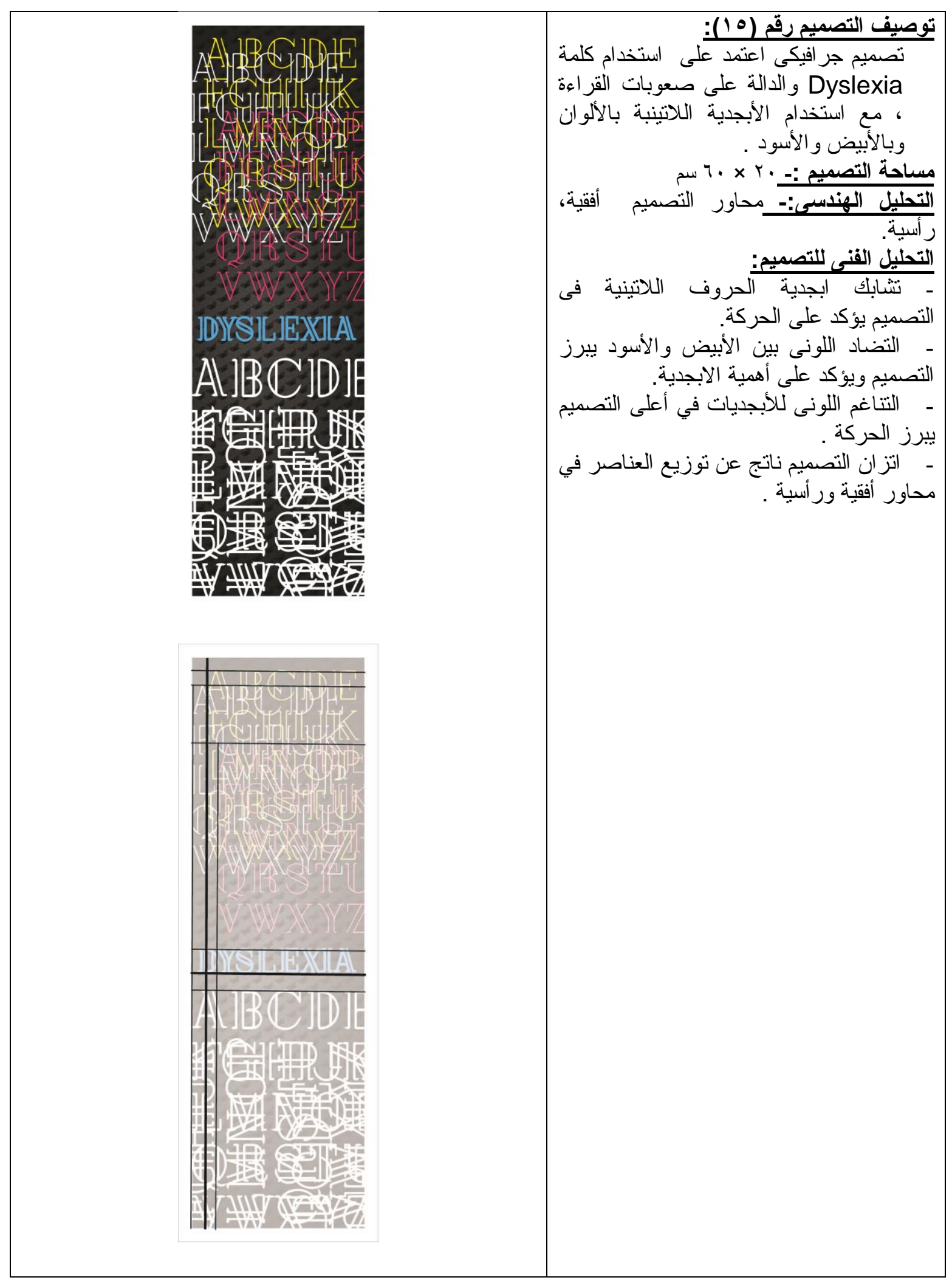

(AmeSea Database - ae -January- April. 2018- 0285) 


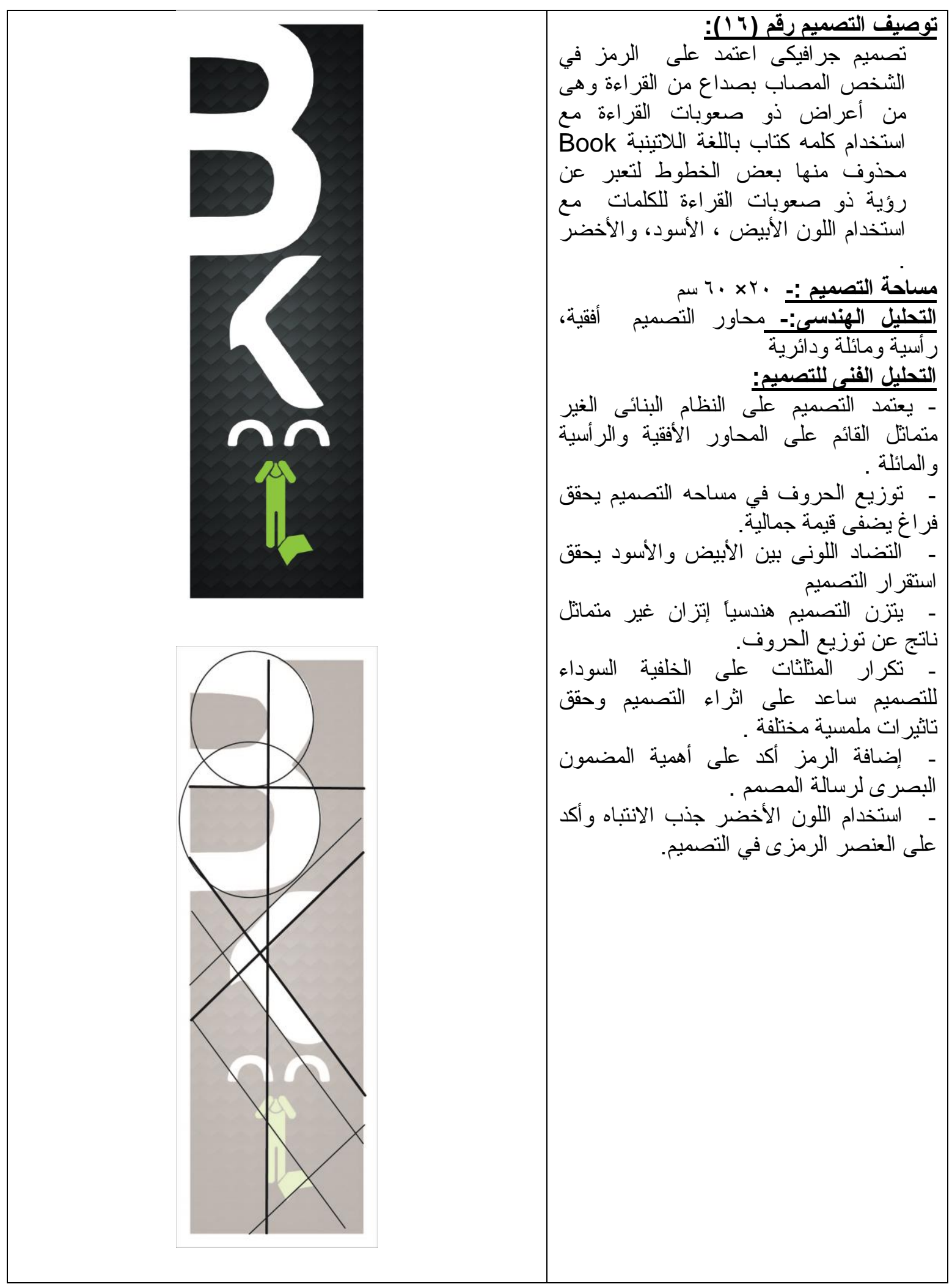

(AmeSea Database - ae -January- April. 2018- 0285) 


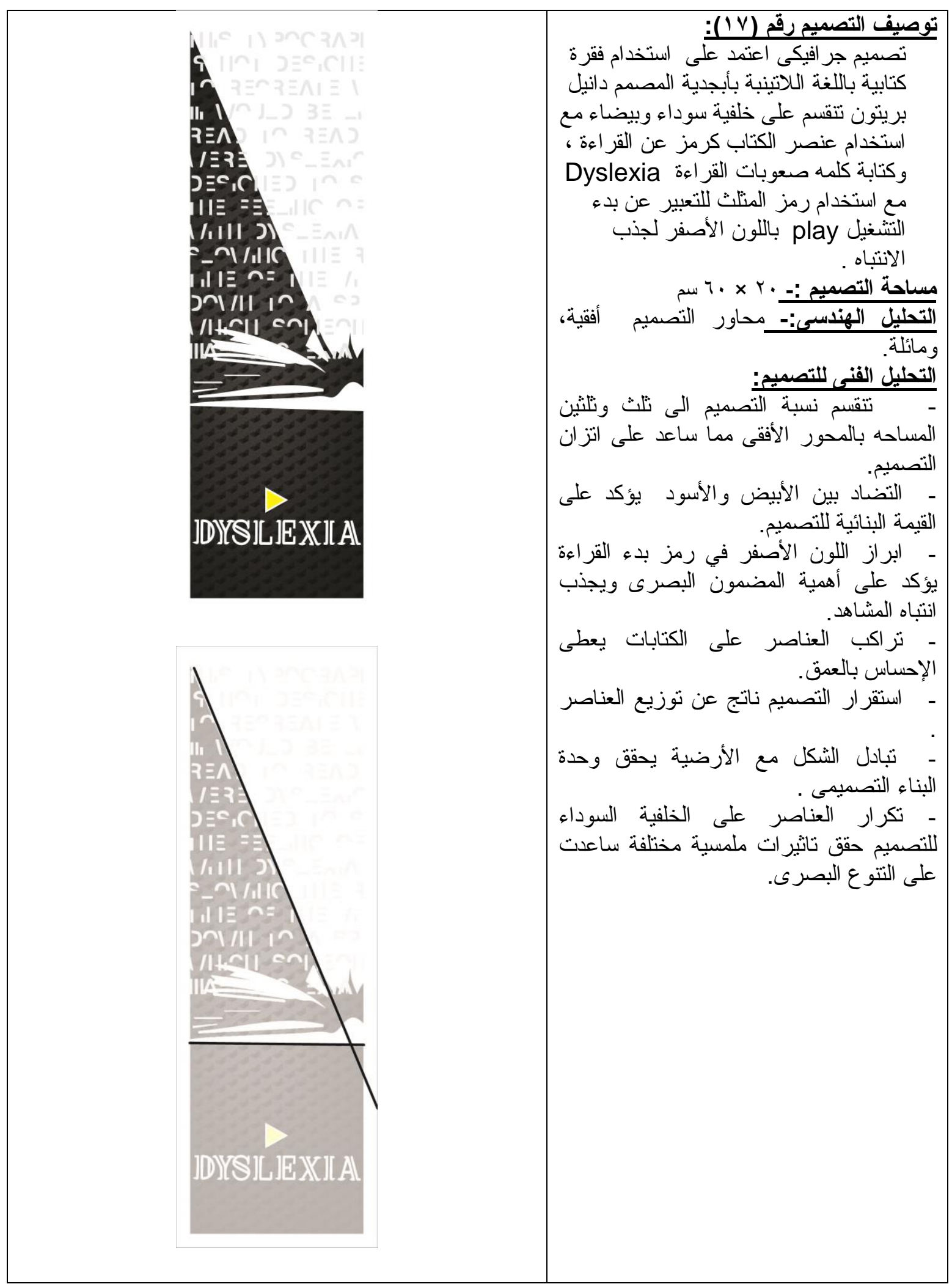

(AmeSea Database - ae -January- April. 2018- 0285) 


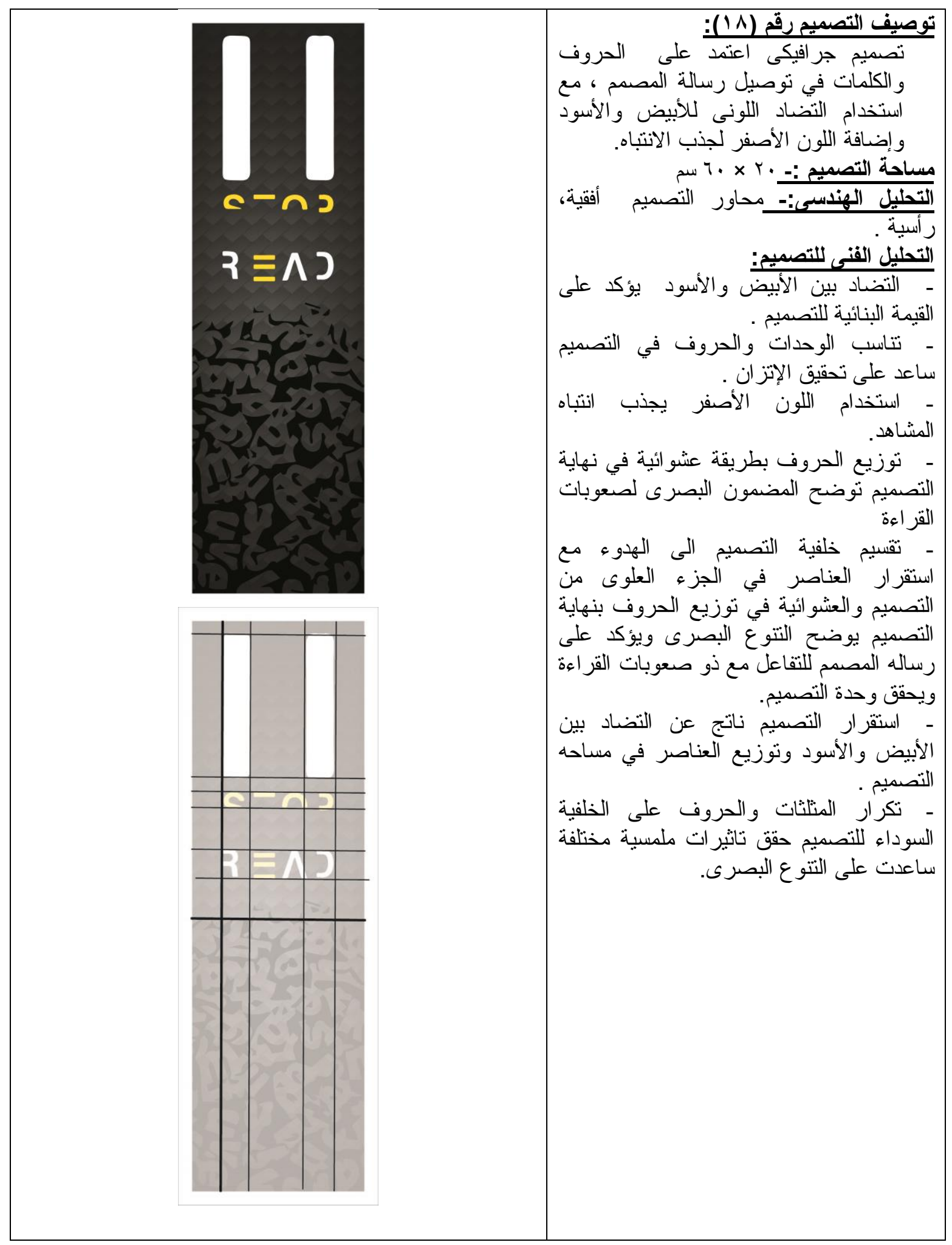

(AmeSea Database - ae -January- April. 2018- 0285) 
جاءت نتائج التجربة بقبول رو اد المعرض للوحات و التقاعل مع اللوحات التصميمية و تتضمن

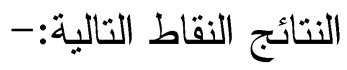

ا. يمكن استثمار التصميم من خلال برامج الكمبيوتز للتعبير عن مشكلات ذو صعوبات القز اءة. - ماء.

r. النظام البنائى للحروف والكتابات والأرقام لها دورا هاما فى توصيل مشكلات ذوى

صعوبات القر اءة من خلال حلول تصميمية مختلفة .

r. فن التيبوغر افى من الفنون التي يمكن من خلالها نشر الوعى بمشكلات صعوبات القراءة منهاء

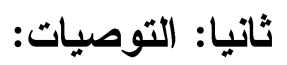

من خلال التجارب التى قامت بها الباحثة تكونت لديها مجموعة من التوصيات للادارسين

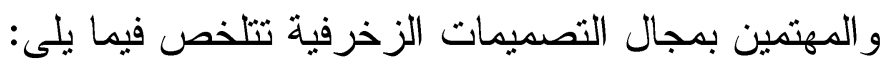
1- الاهتمام بذوى صعوبات القر اءة .

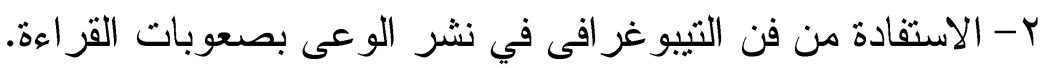
ب- على المصمميين التربويين الاهتمام بالتعبير عن المشكلات المجتمعية.

1. Luz Rello, Ricardo Baeza-Yates: "Good Fonts for Dyslexia", Bellevue, Washington, USA, 2013.

2. John Stein: "the Magnocellular Theory of Developmental Dyslexia", university laboratory of physiology, Oxford, UK, john Wiley \& sons, Ltd, 2001.

3. Michal Erlhoff, Tim Marshall:" Design Dictionary", Birkhäuser Verlag AG, Berline 2008.

4. Kristin Cullen:"Design Elements Typography", Fundamentals Rockport publishers, 2012.

5. "Understanding Dyslexia, Introductory Notes", Lucid Research Ltd , F19 v 02.3 Apr 2006, www.Lucid-Research.com

6. http://metro.co.uk/2015/06/06/this-is-what-it-is-like-to-havedyslexia-5232994/\#ixzz482MyLsoh

7. http://www.new-educ.com 


\section{ملخص البحث}

يهتم العالم بوجه عام بصعوبات القر اءة ، و التي تؤثر في الطريقة التي يتعلم بها الثخص

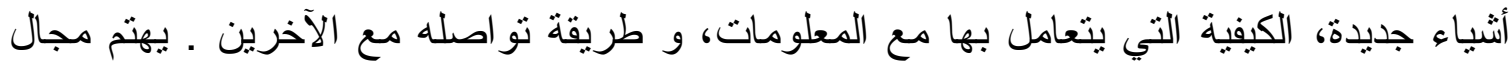

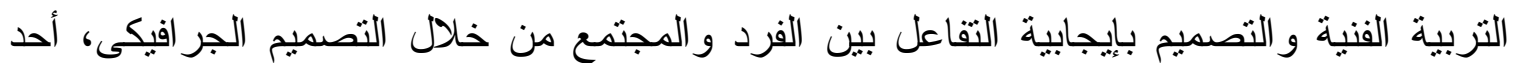

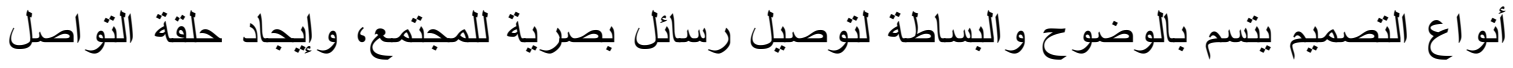

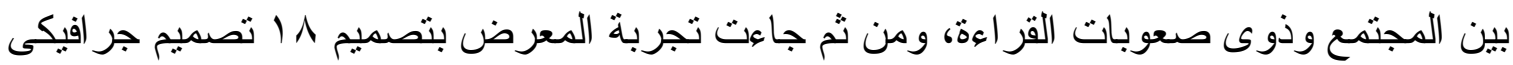

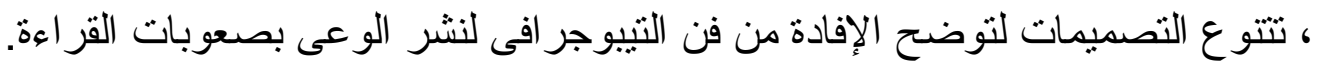
يتضمن المعرض ب محاور: المحور الأول : تصميمات تعتمد على التعبير الصورى ( أنثال ـ رموز ). المحور الثانى : تصميمات تعتمد على الوحدات الكتابية ( حروف ـ كلمات). المحور الثالث : تصميمات تعتمد على الجمع بين التعبير الصورى ، و والوحدات الكتابة الكتابية.

World is caring in general about Dyslexia, Which affect in the way a person learns new things, how he deals with information, and how he communicates with others. The field of art education and design are interested by Positive interaction between the individual and community through graphic design, a type of design is clear and simple to deliver visual messages, and find connection between community and dyslexics, and then came the exhibition experience with 18 graphic designs, designs are varied to explain the benefit of typography art to Raising awareness of dyslexia.

The exhibition includes 3 axes:

- The first axis: Designs based on the image expression (forms symbols).

- The second axis: Designs based on written units (letters - words).

- The third axis: Designs based on the combination of image expression, and written units. 